\title{
INFORMED CONSENT;
}

\begin{abstract}
A SURVEY OF KNOWLEDGE, AND PRACTICE OF INFORMED CONSENT AMONG DENTAL PRACTITIONERS IN HYDERABAD CITY PAKISTAN.
\end{abstract}

1. BDS, M Bioeth, M.Sc Senior Lecturer Department of Prosthodontics Institute of Dentistry LUMHS, Jamshoro.

2. BDS, M.Sc Senior Lecturer Department of Oral Medicine \& Periodontology Institute Dentistry LUMHS, Jamshoro.

3. BDS, FCPS

Associate Professor

Oral \& Maxillofacial Surgery Department Institute of Dentistry, LUMHS, Jamshoro.

4. BDS, M.Sc Lecturer Department of Operative Dentistry Institute of Dentistry, LUMHS, Jamshoro.

5. BDS, M.Sc Lecture Department of Prosthodontics Institute of Dentistry, LUMHS, Jamshoro.

Correspondence Address: Dr. Ramesh Lal Flat No: $4094^{\text {th }}$ floor Citizen Plaza Opp Aga Khan Hospital Main Jamshoro Road, Hyderabad. ramesh.lal@lumhs.edu.pk

Article received on:

07/12/2016

Accepted for publication:

10/03/2017

Received after proof reading: $06 / 05 / 2017$
Dr. Ramesh Lal ${ }^{1}$, Dr. Vikram Pal ${ }^{2}$, Dr. Suneel Kumar Punjabi ${ }^{3}$, Dr. Naveen Khawaja ${ }^{4}$, Dr. Mehwish Shoro ${ }^{5}$

ABSTRACT... Objectives: The objective of this study was to assess the knowledge and practice of informed consent among dental practitioners in Hyderabad city, Pakistan. Study Design: Descriptive cross sectional survey. Setting: Liaquat University of Medical and Health Sciences, Isra University and Dental practitioners working at private Dental clinics in Hyderabad city. Period: This study was conducted over period of six months from November 2015 to April 2016. Material and Method: This study used self-administered structured questionnaire, of consist of ten questions to assess the knowledge and practice of dental practitioners towards informed consent. Data was collected by visiting offices of the study participants at their work place or through email and courier with prepaid envelope where needed. The participants were sent two reminders at the interval of fifteen days to return the filled survey form. The responses were represented in form of percentages. The t-test was used to determine the association between the knowledge and qualification, clinical experience, and age. A significance level of $p<0.05$ was considered as statistically significant. Results: Our response rate was $86 \%$ (103). Majority of the dentist merely knows the meaning of informed consent and overall had poor knowledge (mean score $7.84 \pm 2.44$ ). The analysis showed that years of clinical practice and qualification was statistically significant with mean knowledge score $(p<0.01)$. The verbal form of consent was most preferred method of obtaining informed consent that accounted for $82 \%$ of study participants. $89 \%$ of dentist obtained informed consent from parents when treating their children. Conclusions: From this study, it can be concluded that vast majority of dentist are unaware of informed consent process and their basic requirement. Although majority of dentist believe that informed consent play an important role in routine dental practice yet many of them did not use written form of informed consent. Our results would help the educators and policy makers to develop educational instruction on bioethics with special emphasis on informed consent.

Key words: Informed Consent, Patient's Rights, Information, Dentist.

Article Citation: Lal R, Pal V, Punjabi SK, Khawaja N, Shoro M. Informed Consent; A survey of knowledge, and practice of informed consent among dental practitioners in hyderabad city pakistan. Professional Med J 2017;24(5):772-777.

DOI: 10.17957/TPMJ/17.3767

\section{INTRODUCTION}

Patients' informed consent is a legal regulation and a moral principle. It signifies patients' rights to take part in the clinical decisions about their treatment. In order to practice in a professionally responsible manner, dentists must assist patients to make well-informed decisions about their treatment procedures. ${ }^{1,2}$ This hard decisionmaking process is first primary requirement of good dental practice. Informing the patient and making him an autonomous agent is an integral part of health profession, and deontological duty of every dentist. ${ }^{2}$ Informed consent is often perceived as necessary for legal protection against malpractice claims. However, morally also patients have the right to self-determination and respect for it strengthens the relationship of trust considered so important for clinical success. ${ }^{3}$ Due to increasing awareness of patient's rights the situation is changing across the globe; patients are demanding better and more information about their oral health care. ${ }^{4}$ The Hippocratic Oath that granted doctors the right to decide in the patients' best interest now seems to be in conflict with the $21^{\text {st }}$ century trend of patient's autonomy. The ethical principle of respect for autonomy finds its main application when the informed patient takes part in the decision- 
making process, in proportion to his/ her age and capacity to understand. Informed consent in not a mere written word, and should not be looked on as a legal necessity and a duty, but rather as a virtue of good dental practice. ${ }^{5,6}$ However, the doctor-patient relationship in Pakistan is somewhat different from that in developed world; it is primarily governed by the trust of patients, the doctor is an authority figure and considered the right person to decide treatment modalities. ${ }^{5,6}$

There are several reports of litigation against dentist across the globe where patients have concluded that their clinician have failed to provide sufficient information about the outcomes of selected treatment. 7,8 Fortunately, dental practitioners in Pakistan are immune to litigation, due to multitude of reasons. One there is no structured law on taking informed consent. Secondly the patients are unaware of their rights for autonomous decisions making. Third there is low level of literacy. Nevertheless, there are several reports and complains of malpractice and paternalism by dental practitioners in Pakistan. ${ }^{6}$

Extensive literature search was conducted to develop an understanding of the knowledge, and practices of dental practitioners in Pakistan about informed consent, however, very few studies were found in the local context. It may be safely concluded that, the practice of patient's informed consent is the most ignored part in dental practice in the country. Majority of dentist do not realize the importance of informed consent due lack of the knowledge. In a trusting dentist-patient relationship, the dentist must offer appropriate information about all aspects of the treatment and commitments and should ensure that the patient understands all the information. . $^{9,10}$

This study investigated the perception of dental practitioners pertaining to knowledge and practice of informed consent. The present study was conducted in Hyderabad city which is the second largest city of Sindh province and fifth largest city of Pakistan. It is home of second oldest dental institute in Pakistan and first dental school in Sindh province. The population of the city is about 2 million per the records of the city government. ${ }^{11}$

\section{MATERIAL AND METHOD}

This is a descriptive cross sectional survey, using self-administered structured questionnaire carried over a period of six months from November 2015 to April 2016. The participants included dental practitioners registered with Pakistan Medical \& Dental Council (PMDC), working at Liaquat University of Medical Health Sciences, Isra University and dental practitioners working at private Dental clinics in Hyderabad city. Participants who refuse to make signature in informed consent form, incompletely filled questionnaire and participants who failed to return the questionnaires after two reminders were excluded from data analysis.

To maximize the response rate a meeting was held with heads of dental sections at both universities and were explained the purpose and importance of survey and how its results could contribute ethical dental practice in general. Data was collected by visiting offices of the dental practitioners at their work place or through email and courier with prepaid envelope, where needed. The participants were asked to fill the questionnaire and return to the principal investigator at their earliest. The participants were sent two reminders at the interval of fifteen days to return the completely filled survey form.

To ensure the quality of research, a consent form informing the goal of the study was attached. The participants were informed that they are required to fill the survey form anonymously and were given full assurance that the data will be used only for educational and research purposes, without disclosing the identity in any respect. For the purpose of establishing the validity, the questionnaire was pre-tested on 10 dental practitioners (Cronbach's alpha $=0.74$ ) and the amendments were made accordingly. Those participants who were the part of Pre-test were excluded from the data analysis.

The data obtained was subjected to statistical analysis using Statistical Package for Social Sciences (SPSS, version 16, Chicago, Illinois, 
USA). The responses were represented in form of percentages. To determine the significant association between knowledge and clinical practice experience and qualification, the t-test was used for analysis. A significance level of $p<0.05$ was considered as statistically significant.

\section{RESULTS}

Of the 120 questionnaires distributed among the dental practitioners, we received responses from 103 participants with total response rate of $85.83 \%$. Table-I shows the baseline characteristics of study participants. Of the total participants, there were $73(71 \%)$ males and 30 (29\%) females (M: F 2:1). The age range of the participants was between 25-66 years (mean age $39.7 \pm 5.7$ ); of which the highest percentage of participants ranged between $25-35$ years $(60 \%)$. The percentage of study participants based on the academic qualification showed that highest percentage of participants were graduates (59\% $n=61$ ) while $41 \%$ were postgraduates. Regarding clinical experience of practice the $42 \%(n=43)$ of participants have clinical experience in $6-10$ years of range.

\section{Sample Characteristics}

\begin{tabular}{|l|c|}
\hline $\begin{array}{l}\text { Gender } \\
\text { Male }\end{array}$ & $73(70.88 \%)$ \\
\hline Age & $30(29.12 \%)$ \\
\hline $25-35$ & \\
$36-45$ & $62(60.2 \%)$ \\
$>45$ & $32(31.1 \%)$ \\
\hline Qualification & $9(8.7 \%)$ \\
\hline Graduation (BDS) & \\
Post-graduation (Masters/Fellowship) & $42(40.8 \%)$ \\
\hline Clinical Practice Experience & \\
\hline $1-5$ years & $34(33 \%)$ \\
6-10 years & $43(41.7 \%)$ \\
$>10$ years & $26(25.2 \%)$ \\
\hline Table-I. Baseline Characteristics of Study Participants
\end{tabular}

Table-Il. Shows response of the knowledge based questions. Five questions were asked to assess the knowledge of dental practitioners with the mean knowledge scores of study participants were $7.84 \pm 2.44$. It was interesting to note that $88 \%$ of participants were unware of the law concerned with informed consent. The statistically significant difference was noted in the knowledge among study participants with regard to qualification and work experience as shown in Table-III.

\begin{tabular}{|c|l|c|c|c|}
\hline \multirow{2}{*}{ S. No } & \multicolumn{2}{|c|}{ Question } & \multicolumn{2}{c|}{ Response Rate (\%) } \\
Have Some Idea \\
\hline 1. & Do you know; what is informed consent? & $89(86.4 \%)$ & $6(5.8 \%)$ & $8(7.8)$ \\
\hline 2. & Do you know the types of informed consent? & $66(64.1 \%)$ & $24(23.3 \%)$ & $13(12.6 \%)$ \\
\hline 3. & Do you know the requirements of valid consent? & $48(46.6 \%)$ & $38(36.89 \%)$ & $17(14.6 \%)$ \\
\hline 4. & Do you know the informed consent process? & $33(32 \%)$ & $57(55.3 \%)$ & $13(12.4 \%)$ \\
\hline 5. & Do you know the law concerned to informed consent? & $8(7.8 \%)$ & $91(88.3 \%)$ & $4(3.9 \%)$ \\
\hline & Table-ll. Knowledge Based Questions Regarding Informed Consent \\
\hline
\end{tabular}

Table-IV. Shows the responses of questions pertaining to the practice of informed consent among dental practitioners.

\section{DISCUSSION}

Bioethics has recently gained increasing importance in developing countries like Pakistan. However, its teaching in medical and dental institute is still in state of infancy and requires a lot more to be done to meet international standards. ${ }^{5,12}$ There is little formal teaching of ethics both at undergraduate and graduate level and there is a common perception that dental practitioners are not fully aware of even the informed consent process which is a basic element of ethical dental practice. ${ }^{13}$

In the first part of questionnaire we analyzed the dentist knowledge of informed consent with mean knowledge score of $7.84 \pm 2.44$. The results of the current study showed poor knowledge of dental practitioners towards informed consent. 


\begin{tabular}{|l|l|l|}
\hline $\begin{array}{l}\text { Sample } \\
\text { Characteristics }\end{array}$ & $\begin{array}{c}\text { Mean } \pm \\
\text { Standard } \\
\text { Deviation }\end{array}$ & P-value \\
\hline $\begin{array}{l}\text { Gender } \\
\text { Male }\end{array}$ & $\begin{array}{l}7.91 \pm 2.33 \\
\text { Female }\end{array}$ & 0.19 \\
\hline $\begin{array}{l}\text { Age } \\
25-35\end{array}$ & $7.42 \pm 2.31$ & \\
\hline $36-45$ & $7.42 \pm 2.48$ & \\
\hline 45 & $7.32 \pm 2.43$ & \\
\hline $\begin{array}{l}\text { Qualification } \\
\text { Graduation (BDS) }\end{array}$ & $5.78 \pm 2.68$ & $<0.01$ \\
$\begin{array}{l}\text { Post-graduation } \\
\text { (Masters/Fellowship) }\end{array}$ & $9.21 \pm 1.89$ & \\
\hline Clinical Practice & \\
\hline $\begin{array}{l}\text { Experience } \\
\text { 1-5 years } \\
\text { 6-10 years }\end{array}$ & $6.82 \pm 2.38$ & \\
\hline$>10$ years & $8.18 \pm 2.12$ & $<0.01$ \\
\hline $\begin{array}{l}\text { Table-III. Association of Mean Knowledge Score with } \\
\text { Independent Variables }\end{array}$ \\
\hline
\end{tabular}

\begin{tabular}{|c|c|c|}
\hline Question & Options & $\begin{array}{c}\text { Response } \\
\text { rate (\%) }\end{array}$ \\
\hline $\begin{array}{l}\text { Do you think it is } \\
\text { necessary to obtain } \\
\text { informed consent? }\end{array}$ & $\begin{array}{l}\text { Yes } \\
\text { No }\end{array}$ & $\begin{array}{l}89(86.4 \%) \\
1413.6 \%)\end{array}$ \\
\hline \multirow{2}{*}{$\begin{array}{l}\text { Do you obtain informed } \\
\text { consent from patients? }\end{array}$} & \multirow{2}{*}{$\begin{array}{c}\text { Yes } \\
\text { No } \\
\text { In certain } \\
\text { cases, }\end{array}$} & $\begin{array}{l}79(76.7) \\
07(6.8 \%)\end{array}$ \\
\hline & & $17 \quad 16.5 \%)$ \\
\hline $\begin{array}{l}\text { What form of consent do } \\
\text { you take? }\end{array}$ & $\begin{array}{l}\text { Written } \\
\text { Verbal } \\
\text { Both }\end{array}$ & $\begin{array}{c}11(10.67 \%) \\
84(81.55 \%) \\
08(7.42 \%)\end{array}$ \\
\hline $\begin{array}{l}\text { Do you obtain consent } \\
\text { from parents when } \\
\text { treating their children? }\end{array}$ & $\begin{array}{l}\text { Yes } \\
\text { No } \\
\text { In certain } \\
\text { cases, }\end{array}$ & $\begin{array}{cc}92 & (89.3 \%) \\
5 & (4.9 \%) \\
6 & (2.8 \%)\end{array}$ \\
\hline $\begin{array}{l}\text { In which areas of dental } \\
\text { practice do you consider } \\
\text { it is necessary to obtain } \\
\text { informed consent? }\end{array}$ & $\begin{array}{c}\text { All } \\
\text { Surgical } \\
\text { Endodontics } \\
\text { Prosthodontics } \\
\text { Orthodontics }\end{array}$ & $\begin{array}{c}55(53.4 \%) \\
27(26.2 \%) \\
3(2.9 \%) \\
10(9.7 \%) \\
8 .(7.8 \%)\end{array}$ \\
\hline $\begin{array}{l}\text { Table-IV. Set of Five Qu } \\
\text { Rate of Participants R }\end{array}$ & $\begin{array}{l}\text { stion Depicting t } \\
\text { yarding Practice } \\
\text { onsent. }\end{array}$ & $\begin{array}{l}\text { Response } \\
\text { f Informed }\end{array}$ \\
\hline
\end{tabular}

Though $86.4 \%$ of dental practitioners know what informed consent is; yet majority of them responded negatively to subsequent questions being asked to assess the knowledge. It was interesting to note that only $7.8 \%$ of dentist know the law concerned to informed consent while vast majority do not know what are the legal implications of failing to obtain the informed consent. This poor knowledge could be due to lack of formal educational instruction at undergraduate and postgraduate level. In our study statistically significant association was found between clinical practice experience, qualification, and the mean knowledge score.

Dental practitioners who had $>10$ years of clinical experience had more knowledge than those who had 6-10 or 1-5 years of clinical experience. This might be due to greater exposure of experienced dentist to greater volume of patients and their complains, which subsequently persuade practitioner to update their knowledge to provide efficient dental care. The results of our study also shows that the dentist with postgraduate qualification have greater knowledge of informed consent than those with undergraduate qualifications only. In this regard the results of our study are in accordance with study conducted in by Vivek V Gupta et al: among private dental practitioners. ${ }^{14} \mathrm{~A}$ study conducted by Tahir $\mathrm{S}$ et al: in Lahore reported that $87 \%$ of dentist and dental students had knowledge about informed consent. ${ }^{13}$ Though the results are similar to our study on account of merely knowing what informed consent is, yet they contrasted our results in term of overall knowledge score towards informed consent which was poor in our study.

In the second part of questionnaire we analyzed the practice of dentist towards informed consent. On being asked regarding necessity of obtaining informed consent $86 \%$ of respondents believe that it was quite essential to take informed consent. It was surprising that $14 \%$ of respondent did not consider informed consent to be necessary and this could be due to lack knowledge.

In our study $79 \%$ of dentist claimed of obtaining informed consent in every case while $16.5 \%$ take consent in certain cases. Those who reported that 
they did not obtain consent in every case; surgical intervention with potential risk of complication; were the most likely procedures to cause them seek informed consent. The result of our study in this context contrast with the results of a study conducted in Bathinda city India that reveals $100 \%$ of dentist obtained informed consent in all the cases. ${ }^{14}$

Our study revealed very surprising data on question being asked to the type of consent obtained; $82 \%$ of dentist reported that they routinely used verbal consent, $11 \%$ obtained written and $7 \%$ obtained both. The written form of consent provides evidence that patient has been well informed of all aspects of proposed treatment and provide safeguard to the dentist for malpractice claims. Despite of that the percentage of written form of consent in our study is rather low owing to the perception that dentists are immune to litigations. There are multitude of reasons for this perception; One low literacy level and subsequent lack of awareness of patients towards their rights. ${ }^{6,8}$ Secondly there is no structured law on informed consent in particular though there are guidelines laid down by Pakistan Medical \& Dental Council (PMDC) yet they are ineffective indeed. The results of our study with regard to the type of consent obtained, are in contrast with majority of studies conducted worldwide. In study conducted in Srinagar and Belgaum city India reported $85 \%$ and $64 \%$ of dental practitioner obtained written informed consent respectively. ${ }^{15,16}$

In a study conducted by Farahat W, et al. in Khyber Pukhtunkhwa inquired about the perceived importance and limitations of informed consent in dentistry. ${ }^{17}$ The study reported that among the type of consent; verbal consent was found to be the most favored method of obtaining consent accounted for $84.4 \%$ of participants that are in accordance with our results. This could probably be due to the lack of time and excessive patient load which compels the dentist to prefer verbal over written form of consent.

In response to the question on getting parent's informed consent when treating their children. It was encouraging to see that ninety-two (89.3\%) dentist obtained consent from child's parent or guardian in all the cases, while six $(2.8 \%)$ in certain cases and there were only 5 (4.9\%) dentist that they did not obtain parents' consent. The results of our study in this regard are similar to the study conducted in Bulgaria. ${ }^{18}$

In response to the question, "in which areas of dental practice do you consider it is necessary to obtain informed consent". Fifty-Five (53.4\%) dentist answered they obtained consent prior to any type of dental procedures while twentyseven $(26.2 \%)$ reported that they took consent for surgical procedures only. Of the other 10 $(9.7 \%)$ for prosthodontic treatment, 8 (7.8\%) for orthodontics treatment and only $3(2.9 \%)$ for endodontic treatment. One study was found asking the similar question in this context which reported that $87.5 \%$ of dentist took consent prior to any type of dental procedure which are far greater than our results. ${ }^{18}$

\section{CONCLUSION}

In any survey it is always difficult to ensure the truth value of the answer to the questions asked. There always remains the suspicion that respondents either give the answer that they feel will please the author or give what they perceive to be the correct answer, even if it is not what they actually practice in their routine. Nevertheless, to enhance the validity of study and limit this problem; the anonymized self-completion questionnaire was used.

From current study we can conclude that majority of the dentist lack knowledge and unaware of informed consent process and their basic requirements. Our study also reveals that there are very few dentists who obtain written informed consent which is very important in term of evidence if any litigation arises. There is obvious gap in knowledge and practice. Our findings will be of interest to educators and policy makers to develop educational instruction on bioethics with special emphasis towards informed consent. 
There is also need of proper legislature and its implementation to ensure the practice of informed consent. We also recommend further qualitative studies to explore the issue of informed consent. Copyright(C) 10 Mar, 2017.

\section{REFERENCES}

1. Mirza AN. Importance of informed consent in Dentistry. Int Dent Jr of stud Research. 2012; 1: 13-16.

2. Kakar H, Ghambir RS, Singh S et al. Informed consent: Corner Stone in ethical Medical and Dental Practice. J family Med Prim Care. 2014; 3: 68-71.

3. Lal S. Consent in dentistry. Pac Health Dialog. 2003; 10: 102-5.

4. Mallardi V: The origin of informed consent. Acta Otorhinolaryngol. 2005; 25: 312-327.

5. Jafarey AM: Informed consent: views from Karachi. East Mediterr Health J. 2006; 12: 50-55.

6. Jafarey $A M$, Farooqui $A$ : Informed consent in the Pakistani milieu: the physician's perspective. J Med Ethics. 2005; 31: 93-96.

7. Khan RI: Informed consent and some of its problems in Pakistan. J Pak Med Assoc. 2008; 58: 82-4.

8. Shiraz B, Shamim MS, Shamim MS, Ahmed A: Medical ethics in surgical wards: knowledge, attitude and practice of surgical team members in Karachi. Indian J Med Ethics. 2005; 2: 94-96.

9. Moazam F: Family, patient and physician in medical decision making: A Pakistani perspective. Hastings
Cent Rep. 2000; 6: 28-37.

10. Qidwai W, Qureshi H, Azam SI, Ali SS, Ayub S: Perception of bioethics among general practitioners in Karachi. Pak J Med Sci. 2002; 18: 221-226

11. Population Welfare Department Government of Sindh. Available at: http://www.pwdsindh.gov.pk/ districts/hyderabad.htm

12. Jaffery A.M. Bioethics and Medical Education. JPMA. 2003; 53: 5-6.

13. Tahir S, Ghafoor F, Nusarat S, Khan A. Perception of consent among dental professionals. J Med Ethics Hist Med. 2009; 2: 20-25.

14. Vivek V, Bhat N, Asawa K et al; Knowledge and attitude towards informed consent among private dental practitioners in Bathinda city, Punjab, India. Osong Public Health Res Perspect. 2015; 6: 73-78.

15. Yousaf RM, Fauzi ARM, How SH et al. Awareness, knowledge and attitude towards informed consent among doctors in two different cultures in Asia: a cross sectional comparative study in Malaysia and Kashmir, India. Singapore Med J. 2007; 48: 559-565.

16. Kotrashetti V, Kale A, Mamata $H$. Informed consent: a survey of general dental practitioners in Belgaum city. Indian J Med Ethics. 2010; 7: 2-9

17. Farhat W, Qaim F, Ali Shah SM, et al. Informed consent in dentistry: perceived importance and limitations in Khyber Pukhtunkhwa. JKCD 2013; 3: 14-18.

18. Avramova N, Yaneva K. Patients informed consent in dental practice in Bulgaria. OHDM 2011; 10: 80-87.

\section{AUTHORSHIP AND CONTRIBUTION DECLARATION}

\begin{tabular}{|c|c|c|c|}
\hline Sr. \# & Author-s Full Name & Contribution to the paper & Author $=\mathbf{s}$ Signature \\
\hline 1 & Dr. Ramesh Lal & $\begin{array}{l}\text { Development of Research } \\
\text { Question and Study Design }\end{array}$ & \\
\hline 2 & Dr. Vikram Pal & $\begin{array}{l}\text { Data collection and } \\
\text { discussion }\end{array}$ & \\
\hline 3 & Dr. Suneel Kumar Punjabi & $\begin{array}{l}\text { Data analysis and preparation } \\
\text { of manuscript }\end{array}$ & \\
\hline 4 & Dr. Naveen Khawaja & $\begin{array}{l}\text { Data collection and prepared } \\
\text { results }\end{array}$ & \\
\hline 5 & Dr. Mehwish Shoro & $\begin{array}{l}\text { Compiled references and } \\
\text { proof read of manuscript }\end{array}$ & \\
\hline
\end{tabular}

